\section{Road and Rail Transport in India}

An article by C. N. R. Rau in Current Science of March on "The Co-ordination of Road and Rail Transport" reviews recent experience of transport in the Empire both before and during the War, with special reference to India, and endeavours to indicate basic principles of service which should determine both the choice and organization of transport. Discussing the handicaps under which rail transport generally labours, Mr. Rau considers that the plea for a 'square deal' for the railways is well founded. $\mathrm{He}$ suggests that investigation is still required to determine how far co-ordination of inland transport can meet the recognized ideals of service, whether in the transport of goods or passengers, or from the point of view of operating efficiency and safety, and indicates that both road and railway transport services might explore the field of public relations much more thoroughly. Emphasizing the importance of coordination, once it is clear as to the types of traffic best suited for one form or other of transport, he suggests that legislative or Government control, without nationalization, could with a judicious road policy, so shape the transport system of India that the two methods would work as complementary units, each performing the work best suited to itself and rendering the best service to the community.

The value of agreements between the two systems, of mutual recognition, and the organization of road transport with reference to railway stations, for example, by the use of railway stations as bus termini, the interavailability of tickets, publicity of one service on the other, the application of "undue preference" and "common, carrier" clauses to both systems, are among concrete suggestions advanced for the promotion of efficient transport in India, as well as consideration of the establishment of an organization under joint auspices, entrusted with the task of collecting, analysing and collating all relevant inform. ation in regard to problems of common interest. Road operating statistics should be published on the same lines as railway statistics, and the State should insist on the organization of road haulage on the lines adopted by the railways, so that the two systems can negotiate on an equal footing and share the benefits of any co-ordination schemes.

\section{Diesel-Electric Tube Locomotive}

The London Passenger Transport Board is utilizing parts of old railway coaches from the "Central Line" of the underground system for building at its Acton works Diesel locomotives for hauling ballast and. maintenance trains, or for emergency use in the 'tubes'. These duties are at present performed by tank-type steam locomotives. It is arranged to collect current from the live 600 -volt track rail, or be propelled by its self-contained generating set as circumstances may require, and it is capable of hauling a 600-ton train on the level or one of 300 tons up a 1 in 34 gradient. The length of the vehicle is $57 \mathrm{ft}$., its width $8 \mathrm{ft} .2 \mathrm{in}$., its height $9 \mathrm{ft} .5 \mathrm{in}$., and the tare weight in running order is 62 tons
12 cwt. According to the Electrical Review of May 16, only the oil engine and generator with some switchgear had to be purchased in fabricating the train. The passenger compartments of two old driving cars were cut off, leaving the equipment compartments with motors and driver's cabs; these were joined together. The locomotive can be controlled from either end. Its engine is of the Petter 'superscavenge' airless injection, two-stroke cycle, cold starting type. The six cylinders develop 506 b.h.p. at 675 r.p.m. The engine is started by means of compressed air at $350 \mathrm{lb}$. per sq. in. The generator, which was made by the Brush Electrical Engineering Co. Ltd., is a level-compounded shunt machine with a continuous rating of $750 \mathrm{amp}$. at $450 \mathrm{v}$. The traction equipment consists of two series-parallel sets with automatic relay controlling notching.

\section{Control of Pig Raising}

C. P. McMrezan has furnished what, in view of the present food situation, should prove a valuable analysis of the growth and development of the pig with special reference to carcass quality characters. The five parts (J. Agri. Sci., 30, 1940; 31, 1941) with their appendixes have been conveniently issued together. The aim of the work is to provide a base from which to control the raising of pigs as meatproducing animals. It is, therefore, particularly concerned with the effects of nutrition upon not only the growth and size of the pig as a whole but also upon the quality of the meat produced. The author admits that the term 'meat quality' is not possible of exact definition in a form capable of universal application, but some approximation can be made thereto. Of course it will vary with the use to which the meat is to be put and also with the local tastes and requirements. The bulk of the memoir is naturally concerned with the statement of a number of experiments and an analysis of their results, but general ideas are not overlooked and the work concludes with a review of the main principles that emerge and their wider application even to human beings.

\section{British Natural History}

Despite the increasing difficulties and demands upon the spare-time, amateur as well as professional, natural history continues in Great Britain. The summer Bulletin of the British Empire Naturalists' Association records the continuance of branch activities at Bournemouth, Merseyside, Derbyshire, North Cotswold, London, Manchester and Lancaster ; in fact only two branches have closed since the outbreak of war. 1941 field records include the first definite nesting of the fulmar on St. Bee's Cliff, Cumberland; Bewick's swans and a green sandpiper on spring passage in Lancashire; a fire-crest at Stanmore, Middlesex, on April 6 ; siskins at Farnham, Surrey, April 30, and a bird migration survey over twelve counties. The 1940 edition of the Burtonon-Trent Natural History and Archæological Society records has appeared and directs attention to the opportunity for studying the changes the war-time felling of woods will have upon bird, plant and insect life. 